\title{
Schizophrenia: effects of aripiprazole in metabolic syndrome
}

\author{
Deborah Galvão Coelho da Silva ${ }^{1}$, Luiz Kae Sales Kanazawa ${ }^{\circledR 1}$, Débora Dalla Vecchia ${ }^{1 *}$
}

${ }^{1}$ Federal University of Paraná, Curitiba, Paraná, Brasil

\begin{abstract}
Schizophrenia, in general, is characterized by severe and disabling mental alterations, characterized by the impairment of one's mental, behavioral and social activities, developing certain clinical symptoms, relevant to the diagnosis. The drugs used for the reversion of the symptoms cause several adverse effects that affect the patient's health and well-being, such as motor, endocrine and cardiovascular damages. For a long time, little was known about the origin and the treatment of schizophrenia, which has become a curiosity for science, originating countless researches and theories that are background for several treatments. It is known that alterations in dopaminergic pathways are related to the development of the symptoms of the disease, and evaluating these symptoms, the diagnosis is made and the treatment is initiated. The insertion of new drugs with different characteristics and mechanisms tends to be an advance in the treatment of schizophrenia, as well as reducing the occurence of adverse effects or not worsening already existing cases. Aripiprazole is an innovative atypical antipsychotic employed in the pharmacotherapy of schizophrenia, which tends to attenuate the symptoms, inducing few adverse effects compared to other drugs that are already used, and promotes better quality of life to patients.
\end{abstract}

Keywords: Schizophrenia. Pharmacotherapy. Antipsychotics. Aripiprazole. Metabolic Syndrome.

\section{INTRODUCTION}

Schizophrenia is a severe and disabling mental disorder that commonly appears in the transition of adolescence to the adult phase, characterized by the impairment of cerebral, behavioral and social functions (Falkai et al., 2006). It is one of the most intriguing and studied psychic conditions, due to its clinical and psychopathological characteristics, in which individuals are affected in the height of their productive potentital, being its progression chronic and disabling (Nicolino et al., 2011).

The different symptoms caused by schizophrenia seem to result from the malfunctioning of different neuronal networks. It is known that alterations in dopaminergic pathways are the main ones involved in the development of the symptoms of this disease (Rang et al., 2016). Alterations in the mesolimbic pathway seem to be more related to the development of the positive symptoms, while alterations in the mesocortical pathways are more related to the origin of the negative symptoms

\footnotetext{
*Correspondence: D. D. Vecchia. Departamento de Farmacologia, Universidade Federal do Paraná (UFPR). Rua Coronel Francisco Heráclito dos Santos, 100, 81531-980 Curitiba - PR. Brasil. Phone: +55 42 99905-5410. E-mail: debadv@hotmail.com
}

of the disease. Such positive symptoms usually appear in the beginning of the disease, developing abnormal cerebral functions, including delirium, hallucinations, disorganized speech and abnormal psychomotor behavior, such as catatonia. As for the negative symptoms, they are characterized by the reduction of total loss of normal behavioral functions, causing impairments such as alogy (lack of coherence in speech and organization of ideas), affective flattening, avolition (low goal-directed actions) and inconcise speech, being that these symptoms accompany the patient throughout their entire lives (Golan et al., 2014).

Considering that schizophrenia is a disease of idiopathic cause, it was not until fairly recently that a fair number of studies that correlated its origin with possible treatments were made, and the resources to treat the patients are scarce and not well known. Thus, the insertion of antipsychotic medication was a primordial fator of change in this scenario, as later, individuals were instructed towards to the correct treatment, associating them with symptoms that were pertinent to the disease. The antipsychotics are divided into two therapeutic classes that differ from one another basically by therapeutic potency and relative affinity to receptors, so that such affinities are directly related to the clinical efficacy, 
therapeutic response, as well as to the development of adverse effects (Silva, 2006).

This work aims to address physio- and psychopathological aspects of schizophrenia in order to correlate the already known pharmacological treatments with new drugs inserted in therapeutic, evidencing aripiprazole and its pharmacological activities in schizophrenia, which seem to significantly improve quality of life and the maintenace of the patient's health.

\section{MATERIAL AND METHODS}

The present study was written in the form a review article, using data from literature. For this, books regarding this subject were used, such as: Katzung, Goodman, Rang \& Dale, Golan, Penildon and Silva, etc. Research in databases was made, such as NCBI, Pubmed, Scielo, LILAC, among others, through key-words where a relation between schizophrenia, antipsychotics, dyslipidemia and antipsychotics, atypical antipsychotics, aripiprazole and schizophrenia, was made, among other ones pertinent to the subject. The articles were selected based on the relevance towards the subject in question, so that a justification based in literature would be described, prioritizing studies of more recent publication date, from 2000 to 2018.

\section{Schizophrenia}

Schizophrenia is a severe and disabling mental disorder, characterized by the occurence of one or more psychotic episodes that affect the sense of reality. It usually affects young people and persist throughout life, and may develop serious complications in the patient (Wirshing, 2004). Clinical manifestations are classified in two categories, according to symptomatology: positive and negative symptoms (Brunton, Chabner, Knowmann, 2012).

Positive symptoms are related to the development of abnormal functions and usually appear in the beginning of the disease, in the diagnostic phase. Such symptoms include delirium (distortion in the interpretation and perception), hallucination (abnormal auditive perceptions), catatonia (involuntary blunt movements, static position, muscular stiffness, bizarre posture, sometimes voluntary, stupor), among others that affect cerebral function. The negative symptoms are characterized by the loss or reduction of normal behavioral activities, leading to the development of symptoms such as affective flattening, anhedonia, alogy, avolition, social retraction, among others that are evident in the chronic phase of the disease, accompanying the individuals throughout life (Falkai et al., 2006).
Although schizophrenia does not present a definite origin, it is believed that it is a disease of multifactorial cause, that is, there are several hypothesis studied until today that aim to explain the variables of the causes and contribute to the adequate treatment (Helbert, 2014).

\section{Genetic theory}

The genetic theory presents a combination of genetic and environmental factors, which indicated that the individual may present a genetic polymorphism that predisposes them to schizophrenia, however exposure to environmental factors is necessary for the development of the disease. There is strong but incomplete hereditary evidence, that indicate that in first degree relatives, the risk of developing the disease is around $10 \%$, but in identical twins, if one presentes schizophrenia, the probability that the other one has the characteristic genes is $50 \%$, which indicates that, for the development of schizophrenia in this one, exposure to environmental factors is necessary (Rang et al., 2016).

\section{Neurodevelopmental theory}

This hypothesis supposes that the development of schizophrenia is related to possible neuroanatomical alterations that occur during the brain embryonic phase, so that these alterations do not seem to show until adolescence and the beginning of the adult phase. In addition, environmental and epigenetic factors (inherited genetic modifications) seem to have a direct relation with neurodevelopment, so that the earlier the contact with external factors happen, such as maternal viral exposure or obstetricial conditions that may put fetal formation at risk, such as lack of necessary supplements for neuronal formation, such as glucose, iodine and iron, reduction in oxygen supply, among others, might lead to the poor development of the central nervous system (CNS) (Londero et al., 2015).

\section{Dopaminergic theory}

The dopaminergic theory is the best-accepted theory nowadays and the most used in the clinical diagnosis of schizophrenia. This theory takes into account that the disease is caused by an overproduction or dysregulated production of dopamine (DA), or by an increased sensibility of the dopaminergic receptores in different brain regions (Golan, et al., 2014).

It is believed that the dysregulation in dopamine levels in schizophrenic patients occurs in specific 
brain regions, and these regions are responsible for the development of the several characteristic symptoms. The mesolimbic pathway seems to be related to the development and maintenance of emotions and memory, and the result of a hyperactivity in this region is associated with the appearance of the positive symptoms. As for a hypoactivity in the mesocortical pathway, it affects frontal brain regions that are responsible for the development of normal brain function, such as attention, oriented behavior and planning; so that such behaviors may be related to the development of the negative symptoms (Falkai et al., 2006).

Some studies indicated that drugs of abuse that increase DA levels in the mesolimbic pathway such as cocaine, might be related to the development of the positive symptoms of the disease, as well as to the aggressive behaviors. Cocaine acts by blocking the dopamine transporter (DAT), inhibiting the reuptake of the DA from the synaptic cleft (Brunton, Chabner, Knowmann, 2012); and the result of the excessive stimulation of these dopaminergic receptors denotes similar alterations to the positive symptoms of schizophrenia, including euphoria, emotional instability, hallucination, irritability, among others (Costa, Mac, 2012).

Besides dopamine, other non-dopaminergic neurotransmitters, such as serotonin and glutamate, seem to be involved in the pathophysiology of schizophrenia. Some studies suggest that drugs such lysergic acid diethylamide (LSD) can develop a series of cognition changes, paranoia and perception, which ressembles some schizophrenic symptoms, and a possible explanation for this is that these drugs have a structure similar to serotonin and high affinity for serotonin receptors, and that hyperarousal or increased sensitivity of receptors to the drug, promotes the development of symptoms (Howes, Mc Cutcheon, Stone, 2015).There are some hypothesis that indicate that serotonin receptor $\left(5 \mathrm{HT}_{2 \mathrm{~A}}\right)$ antagonists and the blockade of DA receptors constitute an important mechanism for the pharmacological treatment of schizophrenia, so that this is the mechanism of action of second generation antipsychotics (Helbert, 2014). Taking into account that glutamate is the most abundant neurotransmitter in the CNS, some authors suggest that the occurence of the negative symptoms may be related to the antagonism of glutamate receptors (NMDA), which would cause an increase in the levels of synpatic glutamate and consequent stimulation of non-NMDA receptores, being these receptores responsible for the induction of psychosis (Bessan, Pilowsky, 2003).

In order to minimize these symptoms, fundamental drugs for the treatment of schizophrenia were developed, as well as to improve quality of life, causing reduction in psychotic crisis and inserting patients in the society, in order to improve their acceptance (Azevedo et al., 2006).

\section{Pharmacological treatment}

The dopaminergic hypothesis was essential for the development of the first therapeutic classes of antipsychotic agents, called the typical antipsychotics or first-generation antipsychotics. The greatest examples of this class are chlorpromazine, which belongs to the phenothiazine class, and haloperidol, which belongs to the butyrophenone class; the first-generation antipsychotic class (FGA) differ among them in potency, but share the same mechanism of action, the significant blockade of $\mathrm{D}_{2}$ DA receptors. These drugs are associated with few effective results in the control of the negative symptoms of schizophrenia, indicating that this low efficacy might be related to the hypothesis that the negative symptoms are correlated with the hypoactivity of neurons located in the mesocortical region, and that these drugs are not capable of correcting this hypoactivity (Brunton, Chabner, Knowmann, 2012).

Studies show that high potency FGA agents, such as haloperidol, are associated to the occurence of several extrapyramidal effects (EPE), which are characterized by disturbances of movement such as tardive dyskinesia; besides, they are associated to the occurence of sedation, postural hypotension, anticholinergic and adrenergic effects (Irving, Bergman, Adams, 2013). As for the low potency FGA such as chlorpromazine, they are associated to low induction of EPE, but higher risk of sedation, postural hypotension and tachycardia, as well as high risk of anticholinergic and antiadrenergic effects. In a study regarding the efficacy of chlorpromazine as a low potency FGA agent, showed a discrete improvement of therapy with chlorpromazine compared to placebo, however showing more adverse effects related to the treatment (Adams et al., 2007).

Among the EPE caused by FGA, the Neuroleptic Malignant Syndrome (NMS) is the most severe and concerning, because about $10 \%$ of total cases lead to death. The NMS is characterized by catatonia (motor dysfunction), stupor (profound unconsciousness and insensibility to the environment), fever and autonomic instability. After some time, when receptors are hypersensitive to DA, most patients in treatment with FGA show an improvement of the catatonic effects, also called parkinsonian effects. However, after chronic use of these drugs for months or years, around $20 \%$ of individuals may develop tardive dyskinesia, a disturbance of motor activity 
characterized by involuntary and repetitive facial muscles, arms and body. The exact mechanism responsible for this situation is still unknown, but it is believed that it may be related to adaption of receptors, resulting in excessive dopaminergic activity (Golan et al., 2014). However, all antipsychotics may cause significant adverse effects of variable proportions, being chlorpromazine, thyoridazine, haloperidol, among others belonging to the FGA class, the ones showing greater EPE (Falkai et al., 2006).

The large range of adverse effects caused by conventional antipsychotics led to the development of a new therapeutic class for psychosis, called secondgeneration antipsychotic (SGA) drugs, or atypical antipsychotics. These drugs promote better results in the treatment of schizophrenia, because they tend to produce significantly less adverse effects compared to typical antipsychotics, showing more patient adhesion to treatment, contributing to the improvement of quality of life (Azevedo et al., 2006). In addition, they act by minimizing the positive and negative symptoms, due to its different mechanism of action, which make these drugs more effective in the treatment, as well as by lowering suicidal and depressive tendencies, and by the reduction of aggressive and impulsive behavior (Rocha et al., 2010).

The main examples of this group of drugs are: risperidone, clozapine, olanzapine, quetiapine, ziprasidone and aripiprazole. These drugs, in addition to lower induction of adverse effects, seem to be effective in the negative symptoms (Morais, Oliveira, 2010). These more recent drugs show combined DA $\mathrm{D}_{2}$ and serotonin $5-\mathrm{HT}_{2}$ antagonist properties, which suggest that the antagonist action in both $5-\mathrm{HT}_{2}$ and $\mathrm{D}_{2}$ receptor are important for the antipsychotic effect of atypical agents (Brunton, Chabner, Knowmann, 2012). This same group of drugs there also the bexpiprazole and cariprazine that present mechanisms of action similar to aripiprazole, however differ in pharmacodynamic profile. The bexpiprazole has low intrinsic activity at $\mathrm{D} 2$ receptor and has approximately thenfold higher affinity in receptor $5-\mathrm{HT}_{1}$ and $5-\mathrm{HT}_{2}$, potentially enhancing tolerability (Citrome, 2015). Already Cariprazine, when compared to aripiprazole, presente similar activity in receptor D2 and approximately three to thenfold higher affinity in receptors D3 then D2, and although both are effective in the modulation of psychotics disorders, is not known whether there are clinical advantages in drugs that have overlapping activity in D3 receptors over D2 (Ceskova, Silhan, 2018).

Thereby, aripiprazole is the only drug of this class that exhibits partial $\mathrm{D}_{2}$ receptor agonism and $5 \mathrm{HT}_{2}$ antagonism, which gives it an atypical clinical profile of antipsychotic efficacy with limited EPE and less intense (Church, Hamer, Ulbrich, 2010). The partial $\mathrm{D}_{2}$ receptor agonism may regulate DA levels by by an antagonist action in the subcortical and agonist action in the cortical region, thus regulating the positive and negative symptoms (Smith et al., 2008).

Clozapine was the first atypical antipsychotic developed that showed satisfactory improvements in positive and negative symptoms of schizophrenia. In addition, it showed additional advantages regarding the efficacy in refractory cases and cases of complicated treatment. However, it is associated with the occurence of agranulocytosis (reduction or absence of leukocytes), so that in most cases it is employed when the patient does not respond to treatment with other drugs. Patients who use clozapine must follow periodic monitoring of leukocyte levels in order to minimize the impacts caused by the drug (Fleischhacker, Nasrallah, Newcomer et al.; 2005). The other SGAs also show satisfactory results in the treatment of schizophrenia, but do not induce agranulocytosis, which makes them the first choice for the treatment (Golan et al., 2014).

However, the arrival of new antipsychotics brought a series of new adverse effects that show significant implications in the health of patients; this pharmacological variety of atypical antipsychotics is associated not only to the additional therapeutic benefits, but also to the interaction of the drug to certain receptors, that can increase predisposition of a drug to cause adverse effects, being this differential between the adverse effects caused by typical and atypical antipsychotics, that is, the binding capacity and affinity to a certain receptor, as two different antipsychotics may show similar adverse effects for certain types of receptors. On the other hand, an antipsychotic can be more effective in the reduction of symptoms compared to another due to its capacity of adequately binding to a certain receptor (Nasrallah, 2008). Some actions of these drugs in other receptors are demonstrated in Table I.

\section{Adverse effects}

Antipsychotics, in general, seem to be associated to different degrees of adverse metabolic effects, including weight gain and its complications, metabolic alterations such as Diabetes Mellitus type 2 (DM2), compromised lipid profile, hypertension, dyslipidemia and, in some more severe cases, cardiovascular disease (Azevedo et al., 2006). Usually, changes in lipid profile are shown in the first six months of treatment and the drugs that show more propensity to cause these alterations 
TABLE I - Affinity of antypshychotics drugs on receptors

\begin{tabular}{lcccccc}
\hline \multirow{2}{*}{ Drugs } & \multicolumn{3}{c}{ Affinity of receptors } & Minimum \\
\cline { 2 - 6 } & D2 & $\mathbf{5 H T 2}$ & $\mathbf{\alpha 1}$ & H1 & MAch & $\begin{array}{c}\text { effective dose } \\
\text { (Mg) }\end{array}$ \\
\hline Chlorpromazine & ++ & +++ & +++ & +++ & ++ & 100 \\
Haloperidol & +++ & +++ & ++ & +++ & + & 2 \\
Clozapine & + & +++ & +++ & ++++ & ++ & 50 \\
Olanzapine & ++ & +++ & ++ & +++ & ++ & 5 \\
Quetiapine & + & + & +++ & +++ & + & 150 \\
Risperidona & +++ & +++ & +++ & ++ & - & 4 \\
Ziprasidone & +++ & ++++ & +++ & ++ & - & 40 \\
Aripiprazole & ++++ & +++ & ++ & ++ & - & 10 \\
\hline
\end{tabular}

Nasrallah, 2008; Golan, Tashjian Jr, et al., 2014; Helbert, 2014.

are olanzapine, clozapine and quetiapine, and in a lower degree aripiprazole, risperidone and ziprasidone (Foley et al., 2014).

The mechanism by which antipsychotics cause metabolic disturbances is still unknown, but it is assumed that it may be related to the weight gain and peripheric insulin resistance, as well as to the worsening of the pre-diabetic patients' glicemic control, who can develop DM2 (Kato et al., 2015). However, other hypothesis suggest that these alterations independ from weight gain or obesity, but that these antipsychotic drugs can interact with glucose transportes, altering the plasmatic glucose level (Fleischhacker, Nasrallah, Newcomer, 2005).

It is known that the binding of atypical antipsychotics to $5 \mathrm{HT}_{2}, \mathrm{M}$ (muscarinic), and/or $\mathrm{H}_{1}$ (histamine) receptors, have been associated to metabolic alterations that can compromisse the patient's physical well-being (Correia et al., 2008). The drug's affinity to histamine $\mathrm{H}_{1}$ and to $5 \mathrm{HT}_{2}$ serotonin receptors is linked to the weight gain, while the affinity to muscarinic receptors and its blockade is linked to anticholinergic adverse effects, such as dry mouth, constipation, blurred vision, increased prolactin secretion, among others. A meta-analysis indicated that the blockade of $\mathrm{H}_{1}$ receptors may interfere with the suppression of appetite mediated by leptin, an affect that can lead to weight gain and insulin resistance (Smith et al., 2008). Such complications include weight gain, propensity to diabetes and cardiovascular disease, which are probably linked to the antagonist action of certain drugs in these receptors (Rang et al., 2016).

Among the drugs responsible for causing the metabolic disturbances, it is estimated that clozapine and olanzapine may be related to the greater incidence of weight gain in comparison to ziprasidone and aripiprazole, which seem to have minimum or no effect (Muench, Hamer, 2010). There are several studies correlating such weight gain throughout the treatment period with these drugs. The average weight gain estimated to longer than a year is around $1 \mathrm{~kg}$ with aripiprazole and ziprasidone, $1,5 \mathrm{~kg}$ with amisulpride, $2-3 \mathrm{~kg}$ with quetiapine and risperidone, more than $6 \mathrm{~kg}$ with olanzapine and $7,8 \mathrm{~kg}$ with clozapine, including possible significant individual differences in weight gain based to the individual's lifestyle and diet. The risks of weight gain are greater in patients with a first episode of psychosis, who have not been previously exposed to antipsychotic drugs, compared to patients of long-term treatment. Thus, young people that present the first psychotic crises and begin treatment with these drugs are more likely to show weight gain (Viewag, Hasnain, 2012).

Nevertheless, the advances in the treatment for schizophrenia are directed to the development of more selective agents within the current drug classes, as well as a better understanding of pathophysiology, in order to offer a more effective and safer treatment for the patient (Helbert, 2014). Among them, aripiprazole is one of the most recent SGA agent, being associated to a better tolerability, adhesion to treatment, less intense EPE and low weight gain, which suggests less metabolic alterations which affect the patient's health in comparison to other drugs from the same class (Fleischhacker, Nasrallah, Newcomer, 2005).

\section{Metabolic syndrome}

In addition to the several adverse effects related to the use of antipsychotics, the increase of health problems of the schizophrenic population is often times associated 
to a group of cardiovascular risk factors usually correlated to greater abdominal fat deposition and peripheric insulin resistance, wich predisposes the patient not only to diabetes, but also to the development of other comorbidities, such as, obsesity, arterial hypertension (AH) and dyslipidemia, a situation named Metabolic Syndrome (MS). The life expectancy of these individuals is reduced by about $20 \%$ when compared to the general population, due to clinical conditions of the disease, such as weight gain, diabetes, metabolic syndrome and cardiovascular disease (Cordioli et al., 2014). It is worth mentioning that the association of MS with cardiovascular disease, increases general mortality rates in about 1,5 times and cardiovascular mortality rates in about 2,5 times (Brandão et al., 2005).

Studies show that psychiatric patients have a greater risk of developing MS. Data from the Clinical Antipsychotic Trials of Intervention Effectiveness (CATIE) project, indicated that around $40 \%$ of these individuals develop MS, with a percentual of $51,6 \%$ of women and $36 \%$ of men (McEvoy et al., 2005). According to $\mathrm{WHO}$, the evaluation of insulin resistance and the disturbance of glucose metabolism are the main starting point to evaluate these physiological alterations. The National Cholesterol Education Program (NECP) described the components of the syndrome in order to facilitate its diagnosis, and the work is known as ATP III (Adult Treatment Panel). According to the NCEP-ATP III, MS represents the combination of at least three of the following components: abdominal obesity, alteration in the levels of triglycerides and HDL lipoproteins, hypertension, increased fasting blood sugar and hyperinsulinemia (Brandão et al., 2005). The criteria for the diagnosis of MS according to the NCEP-ATP III are shown in the Table II.

The factors related to the development of MS in schizophrenic patients are partly influenced by aspects of the disease, such as the negativ symptoms and vulnerability to stress, which reflects in a sedentary lifestyle, lack of regular physical activity, bad eating habits, use of doping substances and high levels of smoking. On the other hand, the antipsychotics used for the treatment of schizophrenia have been largely correlated to the manifestation of these alterations due to the propensity of inducing weight gain (Hert et al., 2009).

Obesity and specifically abdominal obesity associated to insulin resistance is considered to be the fator by which the excessive weight leads to glycemic metabolic dysfunctions. This insulin resistance promotes greater liberation of free fatty acids in the bloodstream, mainly by the abdominal adipose tissue, consequently,
TABLE II - Components of metabolic syndrome according to NCEP-ATP III

\begin{tabular}{lc}
\hline Components & Levels \\
\hline $\begin{array}{l}\text { Abdominal obesity through } \\
\text { abdominal circumference }\end{array}$ & \\
Men & $>102 \mathrm{~cm}$ \\
Women & $>88 \mathrm{~cm}$ \\
Triglycerides & $\geq 150 \mathrm{mg} / \mathrm{dL}$ \\
HDL cholesterol & $<40 \mathrm{mg} / \mathrm{dL}$ \\
Men & $<50 \mathrm{mg} / \mathrm{dL}$ \\
Women & $\geq 130 \mathrm{mmHg} \mathrm{ou} \geq 85 \mathrm{mmHg}$ \\
Blood pressure & $\geq 110 \mathrm{mg} / \mathrm{dL}$ \\
\hline Fasting blood glucose
\end{tabular}

I Brazilian Guideline for Diagnosis and Treatment of Metabolic Syndrome, 2005

less insulin is reuptaken, leading to the development of hyperglycemia and greater risk of develping DM2 (Teixeira, Rocha, 2006).

In some case-control studies, it was shown that hyperglycemia tends to occurs around six weeks after the beginning of the treatment with SGA; some cases were reversed with the interruption of the treatment, which suggests a direct correlation between the drugs in insulin resistance (Church, Hamer, Ulbrich, 2010). It is also possible that the blockade of $5 \mathrm{HT}_{1}$ receptors of the $\beta$ pancreatic cells and the inhibition of insulin secretion by $\alpha$ adrenergic receptors may be pointed as possible causes for DM2 (Pramyothin, Khaodhiar, 2010).

It has been noted an increase in plasmatic levels of leptin in patients after treatment with typical and atypical antipsychotic agentes. Leptin is a proteic hormone produced by adipose cells that acts on the hypothalamus regulating food intake and energetic metabolism (Wirshing, 2004). There is evidence that obese patients are resistant to this effect of leptin, but there is no significant evidence that suggests that these drugs have a direct relation with this resistance, nor that they have a primary effect over the function of $\beta$ pancreatic cells (Peet, 2004).

Besides, there is correlation between the administration of antipsychotic drugs and the induction of dyslipidemias; this mechanism has not yet been completely elucidated, although it is supposed that insulin resistance might be the central factor for this mechanism, as there is alteration of the plasmatic lipid concentration, including reduced serum HDL (high 
density, cholesterol carrier) lipoprotein levels and higher VLDL (very low density, triglyceride carrier) lipoprotein levels (Vieweg, Hasnain, 2012). This increased cholesterol and triglyceride levels is associated to the development of cardiovascular diseases or their worsening, such as ischemia or myocardial infarction; as well as of alterations in laboratory results, such as echocardiogram (ECG), the antipsychotics tend to increase the QT interval (interval of ventricular depolarization and repolarization) which implicates in the development of the torsade points, a type of ventricular arrhythmia that can lead to syncope and progress to ventricular fibrilation and sudden death (Marder et al., 2004).

Correl and cols (2009) performed a short-lasting non-randomized study regarding weight gain and metabolic alterations for a period of 12 weeks in children and adolescents of ages between 4-19 years old that were diagnosed with humor disorders, schizophrenia or agressive behavior, and that had not yet been treated. Prescriptions were made before the patients joined the study, using SGAs, including olanzapine, risperidone, quetiapine and aripiprazole; in order to compare the effects of a drug with the effect of another, doctors were authorized to change the dosage and prescribe other drugs along the study. There were 338 patients that applied for the study, and 272 returned for the follow-up, as 15 of these patients refused to follow the treatment of became incompatible, being placed in the control group. At the end of the first three months of treatment, all drugs had caused fast weight gain, with na increase of $4,4 \mathrm{~kg}$ with aripiprazol, 5,3 $\mathrm{kg}$ with risperidone, $6,0 \mathrm{~kg}$ with quetipaine and $8,5 \mathrm{~kg}$ with olanzapine, compared to $0,2 \mathrm{~kg}$ of the control group.

These results suggest that the weight gain associated to antipsychotic therapy is more pronounced in children and adolescents than in adults. Infant psychiatrists have clinically observed significant weight gain in children during antipsychotic treatment and this is particularly worrisome, due to the long-term effect of excessive weight and obesity in the patient's health and the prevalence of excessive weight seen in children and adolescents in the general population (Fleischhacker, Nasrallah, Newcomer, 2005).

However, it is extremely important to have health vigilance as a way to promote specific healthcare to these patients, in order to minimize the impacts caused by schizophrenia per se and by the other adverse effects caused partly by the drugs, showing patients the importance of treatment adhesion and measuring the risks and benefits that the drugs offer, always prioritizing more safety and efficacy.

\section{Aripiprazole}

Throughout time, it has been noted the need to study and develop new drugs for the treatment of mental disorders such as schizophrenia, in order to search for new mechanisms that are more effective, safe and that show better results in therapy. Among these drugs there is aripiprazole, a second generation antipsychotic that has shown significant better results in the treatment of several mental disorders, such as bipolar disorder, refractory depression and schizophrenia (Sarin, Del Porto, 2009). These indications have been proposed in 2002 by the Food and Drug Administration (FDA), who has approved the indication of aripiprazole for the treatment of schizophrenia in adults and adolescents, for the treatment of bipolar disorder with manic episodes, and recently has also been approved for the treatment of irritability and autism in children and adolescents (Belloso, Loza, 2011).

Aripiprazole has been associated to a significant reduction of the positive and negative symptoms of schizophrenia, and this effectiveness is explained by its different mechanism of action that involves partial agonism/antagonism in different brain regions, where there is dopaminergic hypo- or hyperactivity and the antagonism of $5 \mathrm{HT}_{2}$ serotonergic receptors (Grunder, Kungel, 2006). According to this point of view, in cases were there are high levels of dopamine (such as in the mesolimbic pathway, involved in the positive symptoms), aripiprazole acts as a partial antagonist, reducing dopaminergic activity in this region, while in areas with low dopamine levels (such as the pre-frontal cortex, which is involved in the negative symptoms), the drug binds to the dopaminergic receptors and acts as a partial agonist resulting in an increase of $\mathrm{D}_{2}$ function (Mailman, Murthy, 2010); besides, it promotes $5 \mathrm{HT}_{2 \mathrm{~A}}$ receptor antagonismo modulating serotonin levels. Because it shows different pharmacodynamics, it has been mentioned in some studies as the first third generation antipsychotic (TGA), which is defined as drugs that modulate the complex dopamineserotonin (Londero, Massuda, Gama, 2015).

Due to this therapeutic advance, aripiprazole has shown better tolerability and consequent less aggressive adverse effects in comparison to other antipsychotics; Keck Jr and cols (2003) performed a meta-analysis regarding safety and tolerability of aripiprazole in the acute treatment of schizoaffective disorder, whose more common adverse effects reported to aripiprazole were headache, insomnia and vomiting.

In addition to the low incidence of adverse effects, aripiprazole also shows less metabolic alterations, in comparison to other antipsychotics; although published 
data regarding these alterations is limited, the available information suggest that treatment with aripiprazole is not much assoaciated with the risk of developing diabetes of dyslipdemia or with the incidence of alterations in glucose and lipid levels that can affect the patient's health (Fleischhacker, Nasrallah, Newcomer, 2005). In a shortterm comparative study, the inicidence of hyperglicemia caused by aripiprazole was evaluated in comparison to placebo; the results showed that the use of aripiprazole was well-tolerated, and has reversed the hyperglycemia caused by other antipsychotics (Bowles, Levin, 2003).

Furthermore, the use of aripiprazole is associated with minimal body weight alterations, with an average increase of $0,7 \mathrm{~kg}$ in a short period of 4 to 6 weeks, and around $1,05 \mathrm{~kg}$ in a long-term treatment (Melnik et al., 2010). When compared to typical antipsychotics, aripiprazole shows less risk of promoting akathisia (subjective feeling of internal restlessness), less occurence of orthostatic hypotension, low variations in plasmatic prolactin levels, and little significant alterations in the prolongation of the QT interval of the ecocardiogram (Keltner, Johnson, 2002).

Thus, one can notice that these significant clinical complications such as MS and diabetes can be prevented or even reversed employing an antipsychotic with good clinical safety profile, such as aripiprazole. Besides, it can be hypothesized that aripiprazole, with its superior metabolic profile, can be used as a more rentable first line option to improve or even normalize the metabolic state of patients that develop these disturbances, and can also be employed in cases of treatment resistance (Hert et al., 2007).

\section{RESULTS AND DISCUSSION}

It is known that the wide range of drugs available for the treatment of mental disorders are clinically effective for the treatment of diseases such as schizophrenia, showing significant clinical improvement of symptoms and quality of life for the patients, which sometimes can be the main factors that separate these individuals from healthy individuals.

Many antipsychotic drugs are intimately associated to the occurance of a series of adverse effects that are directly related to their pharmacological profile. However, in cases where the schizophrenic patient is predisposed to develop a primary pathologic condition, such as DM2, obesity, dyslipidemia, hypertension or any other, there must be an evaluation of the cost-benefit of the treatment, taking into account that these drugs can help to develop or attenuate the existing cases. However, the development of new drugs, that have different mechanisms of action, has been cardinal for minimizing these metabolic disturbances, as they may offer better clinical and therapeutic results and safety for the patient.

Thus, exceptionally, aripiprazole has been shown positively superior from other drugs used for the treament of schizophrenia, showing satisfactory clinical profile with good tolerability and lower incidence of adverse effects, and can be employed for the correction of adverse effects caused by the other drugs, such as metabolic syndrome, or in refractory cases.

\section{REFERENCES}

Adams CE, Awad G, Rathbone J, Thornley B. Chlorpromazine versus pla cebo for schizophrenia. Cochrane Database Syst Rev. 2007;18(2)1-15.

Azevedo CLL, Abreu MGB, Guimarães LR, Moreno D, Lobato MI, Gama CS, et al. Sobrepeso e obesidade em pacientes esquizofrênicos em uso de clozapina comparado com o uso de outros antipsicóticos. Rev Psiquiatr Rio Gd Sul. 2006;28(2):120128.

Belloso FJD, Loza AS. Aripiprazol: farmacología, eficacia clínica, seguridad y tolerabilidad en el adulto. Rev Psiquiatr. com. 2011;15(1):1-16.

Bowles TM, Levin GM. Aripiprazole: A New Atypical Antipsychotic Drug. The Ann of Pharmacoth. 2003;37(5):687694.

Brandão AP, Nogueira AR, Oliveira JE, Guimarães JI, Suplicy $\mathrm{H}$, Brandão AA, coordenadores. I Diretriz Brasileira de Diagnóstico e Tratamento da Síndrome Metabólica. Arq Bras Cardiol 2005;84(Supl I):1-28.

Bressan RA, Pilowsky LS. Hipótese glutamatérgica da esquizofrenia. Rev Bras Psiquiatr. 2003;25(3):177-183.

Brunton LL, Chabner AB, Knowmann CB. As Bases Farmacológicas da Terapêutica de Goodman e Gilman. 12th ed. In: Farmacoterapia da psicose e da mania. Porto Alegre: AMGH; 2012. p. 417-454.

Ceskova E, Silhan P. Novel treatment options in depression and psychosis. Neuropsychiatric Dis Treat. 2018;14:741-747.

Church TJ, Hamer DA, Ulbrich TR. Assessment and management of atypical antipsychotic-induced metabolic abnormalities. U.S Pharm. 2010;35(11):41-48. 
Citrome L. The ABC's of dopamine receptor partial agonists aripiprazole, brexpiprazole and cariprazine: the 15-min challenge to sort these agents out. Int J Clin Prat. 2015;69(11):1211-1220.

Cordioli AAV, Kieling C, Silva CTB, Passos IC, Barcellos MT. Manual de diagnóstico e estátiscito de transtornos mentais-DSM V. 5 ed. Porto Alegre: Artmed; 2014.

Correia DT, Guerreiro DF, Coentre R, Gois C, Figueira L. Psicofármacos e Síndrome Metabólica. Acta Med Port 2008;21(3):247-258.

Correl CU, Manu P, Olshanskiy V, Barbara N, Kane JM, Malhotra AK. Cardiometabolic risk of second-generation antipsychotics during first-time use in children and adolescents. JAMA. 2009;302(16):1765-1773.

Costa NS, Mac DMS. Neurobiologia e neuropsicologia na esquizofrenia e no uso de cocaína. Rev Med Minas Gerais. 2012; 22(2):199-205.

Falkai P, Wobrock T, Lieberman J, Glenthoj B, Gattaz WF, Möller HJ. Diretrizes da Federação Mundial das Sociedades de Psiquiatria Biológica para o tratamento biológico da esquizofrenia. Parte 1: tratamento agudo. Rev Psiquiatr Clín 2006;33(Suppl 1):7-64.

Fleischhacker WW, Nasrallah H, Newcomer JW. SecondGeneration (Atypical) Antipsychotics and Metabolic Effects. CNS Drugs. 2005;19(Suppl 1):1-93.

Foley DL, Mackinnon A, Morgan VA, Watts GF, McGrath JJ, Castle $\mathrm{Dj}$, et al. Predictors of type 2 diabetes in a nationally representative sample of adults with psychosis. World Psychiatry. 2014;13(2):176-183.

Golan DE, Tashjian Jr AH, Armstrong EJ, Armstrong AW. Princípios de Farmacologia: A Base Fisiopatológica da Farmacologia. 3rd ed. Rio de Janeiro: Guanabara Koogan; 2014. Agentes antipsicóticos atípicos. p.437-446.

Gründer G, Kungel M. Aripiprazole: Pharmacodynamics of a Dopamine Partial Agonist for the Treatment of Schizophrenia. Intern Pharmacopsychiatry. 2006;39(Suppl 1):21-25.

Helbert M. Agentes antipsicóticos e lítio. Em: Katzung BG, Masters SB, Trevor AJ, editores. Farmacologia Básica e Clínica. 12 th ed. Porto Alegre: AMGH; 2014.
Hert M, Hanssens L, Winkel RV, Wampers M, Eyck DV, Scheen A, et al. A case series: evaluation of the metabolic safety of aripiprazole. Schizophr Bull. 2007;33(3):823-830.

Hert M, Schreurs V, Vancampfort D, Winkel RV. Metabolic syndrome in people with schizophrenia: a review. World Psychiatry. 2009;8(1):15-22.

Howes O, Mc Cutcheon, Stone J. Glutamate and dopamine in schizophrenia: an update for the 21 st century. J Psychopharmacol. 2015;29(2):97-115.

Irving $\mathrm{CB}$, Bergman $\mathrm{H}$, Adams $\mathrm{CE}$. Haloperidol versus placebo for schizophrenia (Review). Cochrane Database Syst Rev. 2013;15(11):1-119.

Kato Y, Umetsu R, Abe J, Ueda N, Nakayama Y, Kinosada $\mathrm{Y}$, et al. Hyperglycemic adverse events following antipsychotic drug administration in spontaneous adverse event reports. J Pharm Health Care Sci. 2015;1(1):1-15.

Keck Jr PE, McElroy SL. Aripiprazole: a partial dopamine D2 receptor agonist antipsychotic. Expert Opin Investig Drugs. 2003;12(4):655-662.

Keltner NL, Johnson V. Aripiprazole: A third generation of antipsychotics begins? Perspect Psychiatr Care. 2002;38(4):157159.

Londero MDB, Massuda R, Gama CS. Neurobiologia da esquizofrenia. Em: Nardi AE, Quevedo J, Silva AG. Esquizofrenia: Teoria e Clínica. $1^{\mathrm{a}} \mathrm{st}$ ed. Porto Alegre: Artmed; 2015.

Mailman RB, Murthy V. Third generation antipsychotic drugs: partial agonism or receptor functional selectivity? Curr Pharm Des. 2010;16(5):488-501.

Marder SR, Essock SM, Miller AL, Buchanan RW, Casey DE, Davis JM, et al. Physical Health Monitoring of Patients With Schizophrenia. Am J Psychiatry. 2004;161(8):1334-1349.

McEvoy JP, Meyer JM, Goff DC, Nasrallah HA, Davis SM, Sullivan L, et al. Prevalence of the metabolic syndrome in patients with schizophrenia: Baseline results from the Clinical Antipsychotic Trials of Intervention Effectiveness (CATIE) schizophrenia trial and comparison with national estimates from NHANES III. Schizophr Res. 2005;80(1):19-32. 
Melnik T, Soares BG, Puga MES, Atallah ÁN. Efficacy and safety of atypical antipsychotic drugs (quetiapine, risperidone,aripiprazole and paliperidone) compared with placebo or typical antipsychotic drugs for treating refractory schizophrenia: overview of systematic reviews. Sao Paulo Med J. 2010;128(3):141-166.

Morais RMO, Oliveira IR. Antipsicóticos. Em: Silva P. Farmacologia. $8^{\circ}$ th ed. Rio de Janeiro: Guanabara Koogan; 2010. p. 313-327.

Muench J, Hamer AM. Adverse effects of antipsychotic medications. Am Fam Physician. 2010;81(5):617-622.

Nasrallah HA. Atypical antipsychotic-induced metabolic side effects: insights from receptor-binding profiles. Mol Psychiatry. 2008;13(1):27-35.

Nicolino PS, Vedana KGG, Miasso AI, Cardoso L, Galera SAF. Esquizofrenia: adesão ao tratamento e crenças sobre o transtorno e terapêutica medicamentosa. Rev Esc Enferm USP. 2011;45(3):708-715

Peet M. Diet, diabetes and schizophrenia. Br J Psychiatry Suppl. 2004;184(47):102-105.

Pamyothin P, Khaodhiar L. Metabolic syndrome with the atypical antipsychotics. Curr Opin Endocrinol Diabetes Obes. 2010;17(5):460-466.

Rang PH, Dale MM, Flower JR, Henderson G. Rang \& Dale Farmacologia. 8th ed. Rio de Janeiro: Elsevier; 2016. Fármacos antipsicóticos. p. 1306-1327.
Rocha FF, Alvarenga NB, Lage NV, Trivelato ALL, Barros AC, Corrêa H. Antipsicóticos atípicos e comportamento suicida em pacientes esquizofrênicos ou esquizoafetivos. Rev Psiquiátr Clín. 2010;5(37):228-232.

Sarin LM, Del Porto JA. Antipsicóticos atípicos na depressão refratária. J Bras Psiquiatr. 2009;58(2):73-78.

Silva, R. Esquizofrenia: uma revisão. Psicol USP. 2006;17(4):263-285.

Smith M, Hopkins D, Peveler RC, Holt RIG, Woodward M, Ismail K. First-v second-generation antipsychotics and risk for diabetes in schizophrenia: systematicreview and meta-analysis. Br J Psychiatry. 2008;192(6): 406-411.

Teixeira PJR, Rocha FL. Efeitos adversos metabólicos de antipsicóticos e estabilizadores de humor. Rev Psiquiatr RG Sul. 2006;28(2):186-196.

Vieweg V, Hasnain M. Schizophrenia, antipsychotic drugs, and drug-induced weight gain and obesity. Expert Rev Neurother. 2012;26(1):19-22.

Wirshing DA. Schizophrenia and obesity: impact of antipsychotic medications. J Clin Psychiatry. 2004;65(Suppl 18):13-26.

Received for publication on $20^{\text {th }}$ January 2018 Accepted for publication on $21^{\text {st }}$ June 2018 